Acoustical interaction between vibrating lips, downstream air column, and upstream airways in trombone performance

Vincent Fréour and Gary P. ScavoneTRM

Citation: The Journal of the Acoustical Society of America 134, 3887 (2013); doi: 10.1121/1.4823847

View online: http://dx.doi.org/10.1121/1.4823847

View Table of Contents: http://asa.scitation.org/toc/jas/134/5

Published by the Acoustical Society of America

Articles you may be interested in

Relationships between pressure, flow, lip motion, and upstream and downstream impedances for the trombone

The Journal of the Acoustical Society of America 137, (2015); 10.1121/1.4908236 


\title{
Acoustical interaction between vibrating lips, downstream air column, and upstream airways in trombone performance
}

\author{
Vincent Fréour ${ }^{\mathrm{a})}$ and Gary P. Scavone \\ Computational Acoustic Modeling Laboratory, Centre for Interdisciplinary Research in Music Media and \\ Technology, Music Technology, Schulich School of Music, McGill University, Montreal, Quebec, H3A 1E3 \\ Canada
}

(Received 15 April 2013; revised 4 September 2013; accepted 16 September 2013)

\begin{abstract}
This paper presents experimental results on the acoustical influence of the vocal tract in trombone performance. The experimental approach makes use of measurements at the interface between the player and instrument, allowing a relative comparison between upstream airways and the downstream air column impedances, as well as an estimation of the phase of the impedance of the upstream and downstream systems. Measurements were conducted over the full traditional range of playing, during sustained tones with varying dynamic, as well as in special effects such as pitch bending. Subjects able to play over the full range demonstrated significant upstream influence in the higher register of the instrument. These players were categorized in two groups according to their ability to control the phase of the upstream impedance and their ability to generate powerful downstream acoustic energy. Sustained tones played with varying dynamics showed a general tendency of a decrease in vocal-tract support with increase in loudness. Although pitch bends did not involve significant upstream influence at $f_{0}$, results suggest modification of the lip behavior during bending. Vocal-tract tuning at tone transitions was also investigated and found to potentially contribute to slur articulations. (C) 2013 Acoustical Society of America. [http://dx.doi.org/10.1121/1.4823847]
\end{abstract}

PACS number(s): 43.75.Fg, 43.75.St, 43.75.Yy [TRM]

Pages: $3887-3898$

\section{INTRODUCTION}

In brass instruments, sound is produced by autooscillations of the lips resulting from an overpressure created by the player in the mouth cavity. These oscillations are sustained by a complex aero-acoustical coupling between the airflow generated at the lips, the lips themselves, the resonances of the downstream air-column and potentially, the resonances of the player's upstream airways. ${ }^{1}$ Although the influence of vocal-tract resonances on woodwind instruments has been the object of significant interest over the last decades, ${ }^{2-8}$ vocaltract influence in brass instruments remains understudied and less well understood.

The objective of this study is to provide experimental results on the influence of the vocal-tract in trombone performance within the context of the linear theory of oscillation, and with the aim of characterizing how skilled players strategically tune their vocal tract during specific playing tasks.

Brass players usually agree on the importance of tongue placement in the control of intonation, timbre, and mastering of the upper register. According to some players, tongue placement is a crucial attribute in the control of the high register; a low tongue position is associated with the low register and a high tongue position with the high register. ${ }^{9}$ Some famous brass players and pedagogues also refer to singing exercises as fundamental training practices. ${ }^{10}$ These different testimonies lend support to the idea that vocal-tract

\footnotetext{
a) Author to whom correspondence should be addressed. Electronic mail: vincent.freour@mail.mcgill.ca
}

adjustments may play an important role in the control of sound production in brass instruments.

Laryngoscopic measurements conducted on brass players showed some laryngeal and pharyngeal adjustments during performance, suggesting a strategic physiological control of the vocal-tract. ${ }^{11-13}$ Although these observations were mostly discussed from a physiological perspective, they may also suggest underlying acoustical tuning of the upstream airways. Electroglottographic recordings conducted on French horn players showed electroglottographic activity during and prior to tone production, suggesting partial abduction of vocal-folds or ventricular bands during playing. ${ }^{14}$

A significant number of studies have focused on the influence of vocal-tract resonances in woodwind instruments. Overall, investigations agree on the ability of proficient players to precisely tune vocal-tract resonances in the range of $500-1500 \mathrm{~Hz}$. These adjustments occur when the downstream impedance becomes weak enough so that a vocal-tract resonance may support or even override the effect of the downstream air column. This was particularly observed in saxophones and clarinets during altissimo playing and for special effects such as pitch bending. . $^{-8,15,16}$

Regarding lip-reed instruments, experiments on the didjeridu ${ }^{17}$ showed anti-resonances in the radiated sound induced by vocal-tract resonances. Wolfe $e t$ al. investigated the influence of upstream resonances in the didgeridoo and trombone performance using an artificial lip reed player. ${ }^{18}$ This system enabled the characteristics of an upstream resonance to be varied (low or high tongue position) while maintaining a fixed reed setting. On both instruments, vocal-tract configuration had an effect on intonation as well as on transitions between two registers; an upstream constriction near 
the valve was able to slightly increase the playing frequency as well as facilitate transition to a higher bore resonance. These results were corroborated by more recent characterizations of the effect of vocal-tract resonances in trumpets, ${ }^{19}$ although this study was only conducted on one subject. In this work, different upstream conditions were characterized from MRI imaging of a trumpet player's vocal-tract and tested through numerical simulations. ${ }^{20}$ Vocal-tract configuration especially appeared to influence the minimum blowing pressure, as well as the natural lip frequency at which transitions between registers are observed. Although these studies appear to confirm a non-negligible influence of the vocal-tract in brass playing, they partly involved analog or numerical simulations of a brass player system and are limited to simple musical tasks, especially in terms of register. Chen et al. performed direct measurements of vocal-tract resonances on trumpet players. $^{21}$ Although this method allows for direct measurement of vocal-tract input impedance at the lips during performance, results did not show consistent tuning strategies from the players. One objective of the proposed study is, therefore, to develop or adapt a measurement technique for in vivo evaluation of vocal-tract influence in trombones allowing for investigation of a variety of playing tasks.

An important characteristic of brass playing relies on the degree of control from the player on the natural frequency of the lips. Lip-valves have been shown to be generally well represented by outward striking reed models. ${ }^{22-27}$ Lip valves are able to oscillate only within a narrow frequency range around their natural frequency. This particularly highlights the fact that brass players must be able to adjust the mechanical properties of the lips and hence tune their natural lip frequency in order to excite the air column at a given frequency. This further suggests that vocal-tract tuning in brass performance may be particularly dependent on the nature of the lip-reed mechanism at the given playing frequency. ${ }^{23}$ Therefore, it could be of great interest to consider both amplitude and phase of downstream and upstream system impedances at the frequency of interest. A second objective of this study is thus to adapt the principle of electrologlottography ${ }^{29}$ to the monitoring of lip transverse electrical impedance on trombone players in order to enable estimation of the phase of the downstream and upstream impedance at the playing frequency and provide further information on the modalities of the interaction between the downstream air-column, the lips, and the player's upstream airways.

\section{THEORETICAL APPROACH}

\section{A. Upstream to downstream impedance ratio}

Assuming continuity of the volume flow at the reed junction, ${ }^{30}$ the following relations between upstream and downstream frequency domain quantities can be derived

$$
\frac{Z_{u}}{Z_{d}}=-\frac{P_{u}}{P_{d}},
$$

where $u$ and $d$ subscripts denote upstream and downstream variables. $P_{d}$, therefore, corresponds to the downstream acoustic pressure created in the mouthpiece, and $P_{u}$ corresponds to the upstream acoustic pressure created at the input of the vocal-tract (i.e., in the mouth cavity just upstream from the lips). $Z_{d}$ and $Z_{u}$ are the input impedance of the downstream air-column and the player's upstream airway, respectively.

\section{B. Phase of upstream and downstream impedances}

According to Elliot and Bowsher, ${ }^{1}$ the downstream lip mobility $G_{d}$ can be defined as

$$
G_{d}=\frac{S_{\text {lip }}}{P_{d}}
$$

where $S_{\text {lip }}$ is the alternating lip opening area. $G_{d}$ is the response of the lip motion to the downstream pressure created in the mouthpiece of the instrument. This expression ignores $P_{u}$, the pressure at the input of the vocal-tract, and thus any influence of the upstream airway. Analogously, the upstream lip mobility $G_{u}$ and the adjusted downstream lip mobility $G$ can be defined as

$$
\begin{aligned}
& G_{u}=\frac{S_{\text {lip }}}{P_{u}}, \\
& G=\frac{S_{\text {lip }}}{P_{d}-P_{u}} .
\end{aligned}
$$

$G_{u}$ is the response of the lip motion to the upstream pressure $P_{u}$, ignoring the influence of the acoustic pressure created in the mouthpiece $P_{d}$, and $G$ is the response of $S_{\text {lip }}$ to the pressure difference across the lips $P_{d}-P_{u}$ and therefore takes into account both downstream and upstream interactions.

Assuming a quasi-static model of flow through the reed channel, the Bernoulli equation that relates the downstream acoustic flow $u_{d}(t)$ and $s_{\text {lip }}(t)$ in the time domain is given by the following expression:

$$
u_{d}(t)= \pm \sqrt{\frac{2\left|p_{0}+p_{u}(t)-p_{d}(t)\right|}{\rho}} \cdot s_{\text {lip }}(t),
$$

where $\rho$ is the average air density, $p_{0}$ represents the quasistatic blowing pressure, and $p_{u}(t)$ and $p_{d}(t)$, the timedependent upstream and downstream acoustic pressures.

Under the assumption that the quasi-static mouth pressure $p_{0}$ is usually much greater than $p_{u}(t)$ and $p_{d}(t)$, Eq. (5) can be linearized to

$$
u_{d}(t) \simeq \sqrt{\frac{2 p_{0}}{\rho}} \cdot s_{\mathrm{lip}}(t)
$$

Equation (6) depicts a linear relationship between $u_{d}(t)$ and $s_{\text {lip }}(t)$, which implies that the two quantities oscillate in phase. The downstream phase condition of regeneration ${ }^{1,22}$ (PCoR) can thus be derived at the fundamental frequency $f_{0}$ from Eqs. (2) and (6)

$$
\angle G_{d}\left(f_{0}\right)+\angle Z_{d}\left(f_{0}\right)=0
$$


Analogously, two other phase conditions of regeneration can be defined from Eqs. (3), (4), and (6)

$$
\begin{aligned}
& \angle G_{u}\left(f_{0}\right)+\angle Z_{u}\left(f_{0}\right)=\pi, \\
& \angle G\left(f_{0}\right)+\angle Z\left(f_{0}\right)=0 .
\end{aligned}
$$

We refer to Eq. (8) as the upstream PCoR, and to Eq. (9) as the adjusted downstream PCoR, where $Z=Z_{d}+Z_{u}$ is the total impedance perceived by the lips.

In sum, Eqs. (7), (8), and (9) give the conditions under which auto-oscillations exist when coupled to both downstream and upstream systems: Eq. (7) alone amounts to neglecting acoustical interaction with the upstream airway, Eq. (8) alone amounts to neglecting the acoustical coupling with the downstream air column, and finally Eq. (9) amounts to considering both upstream and downstream interactions. Under the hypothesis that regeneration occurs on both sides of the lips, Eqs. (7), (8), and (9) show that $\angle G_{d}, \angle G_{u}-\pi$, and $\angle G$ can therefore be considered as estimates, respectively, of $\angle Z_{d}$, $\angle Z_{u}$, and $\angle Z$ at the fundamental frequency of the sound $f_{0}$.

In the low register, our results should be interpreted with care since the complex contact between the lips, as well as lip outward motion may induce a non-negligible non-linearity in the flow equation. However, this should not be the case when the pitch increases and the upward motion of the lips reduces the flow component arising from the lip longitudinal displacement. ${ }^{20,25,31}$ Regarding the effect of collision, as supported by experimental and numerical investigations on vocal-fold vibration, ${ }^{32,33}$ we may reasonably consider that given basic similarities in the behavior of both valve systems, the lip collision during closure does not significantly affect the linear relationship between the volume flow and opening area. During closure, we hypothesize that no volume flow occurs and only residual turbulence is present. ${ }^{32}$ This assumption is supported by the observation of short closed phases in vibrating lips, ${ }^{34,35}$ as well as potential simpler contact during the closed phase as shown by lip electrical impedance measurements. ${ }^{35}$ Furthermore, as supported by Backus and Hunley, ${ }^{36}$ as well as Elliot and Bowsher, ${ }^{1}$ the small lip opening area in the high register increases the flow resistance of the lip orifice, the latter becoming potentially larger than the downstream impedance in the very high register. Consequently, the volume flow at the lips turns out to be proportional to the lip opening for high playing frequencies.

\section{EXPERIMENTAL APPROACH}

\section{A. $P_{d}$ and $P_{u}$ recordings}

A miniature Endevco pressure transducer (8510-B) was inserted through a hole in the cup of the mouthpiece in order to record the downstream acoustic pressure $P_{d}$ (i.e., at the input of the downstream air-column). A second Endevco transducer $(8507-\mathrm{C})$ was used to measure the acoustic pressure at the input of the vocal-tract $P_{u}$ : The transducer was inserted in a small catheter and the subject asked to maintain the extremity of the catheter in the mouth, above the tongue, as close as possible to the internal wall of the teeth. We can then roughly estimate the distance between the catheter extremity and the lips at around $5 \mathrm{~mm}$, which would cause a group delay of $14 \mu \mathrm{s}$, corresponding to a phase shift of about $3.6 \mathrm{deg}$ at $700 \mathrm{~Hz}$ (close to the maximum sounding frequency). The small diameter of the transducer and catheter (about $2.5 \mathrm{~mm}$ ) reduced the obstructiveness caused by the transducer. A relative calibration of the downstream and upstream microphones mounted in the catheter was performed over the frequency range of interest. As both transducers measure acoustic and quasi-static pressure, the low frequency component of the quasi-static mouth pressure $p_{0}$ was extracted by low-pass filtering the upstream transducer signal.

\section{B. Electrical impedance measurement of the lips}

As described in the previous section, our method involves the evaluation of the phase of the lip opening relative to the phase of the acoustic pressure measured on both sides of the lips. Similar measurements of lip motion were performed on French horn players using a strain gauge attached to the player's upper lip, ${ }^{26}$ though this solution was quite invasive for the participant. Moreover, this technique requires a careful calibration in order to correlate the strain gauge signal with the opening and closing phases of the lip motion. Consequently, we propose an alternative approach by measuring the variations of electrical impedance across the lips during playing. This technique is based on the principle of electroglottography developed by Fabre ${ }^{29}$ in 1957 and extensively applied to the monitoring of vocal-fold vibrations; a high frequency alternate current $i(t)$ is generated between two electrodes located across the larynx and variations of vocal-fold contact area during phonation cause amplitude variations of the alternating tension $u(t)$ recorded at the electrodes. After demodulation of $u(t)$, and according to Ohm's law $(u=R \cdot i)$, the resulting signal is hence proportional to the varying amplitude of the electrical impedance $R(t)$ across the electrodes. A somewhat related approach was previously applied on the lips of a didgeridoo player by Wolfe and Smith ${ }^{37}$ in order to simultaneously record vocalfold and lip apertures in didgeridoo performance.

In our setup, two electrodes made of silver-plated copper shielding tape were glued on a Kelly plastic mouthpiece of dimensions equivalent to a Vincent Bach 6 1/2 AL (Fig. 1). The two electrodes were connected to a commercial electroglottogaph signal conditioner (Voce Vista) and the resistance of the electrode pair rose in order to fit with the signal conditioner requirements. The resulting tension recorded at the output of the conditioner is therefore proportional to the electrical impedance across the lips $R_{\text {lip. }}$. As in the case of phonation, the oscillations of $R_{\text {lip }}$ are due to periodic variations of the contact area between the lips. Thus, we can reasonably assume that $R_{\text {lip }}$ and $S_{\text {lip }}$ oscillate in phase at $f_{0}$; when the lips open, the contact area between the lips decreases and $R_{\text {lip }}$ increases; on the contrary when the lips close, $R_{\text {lip }}$ decreases since the contact between the lips becomes larger. Given the purpose of our sensing device, we propose to call it an "electrolabiograph." As far as we know, this term was first proposed by Krakow in 1994 for the study of articulatory lip motions in syllables. ${ }^{38}$ In order to measure the latency of the 


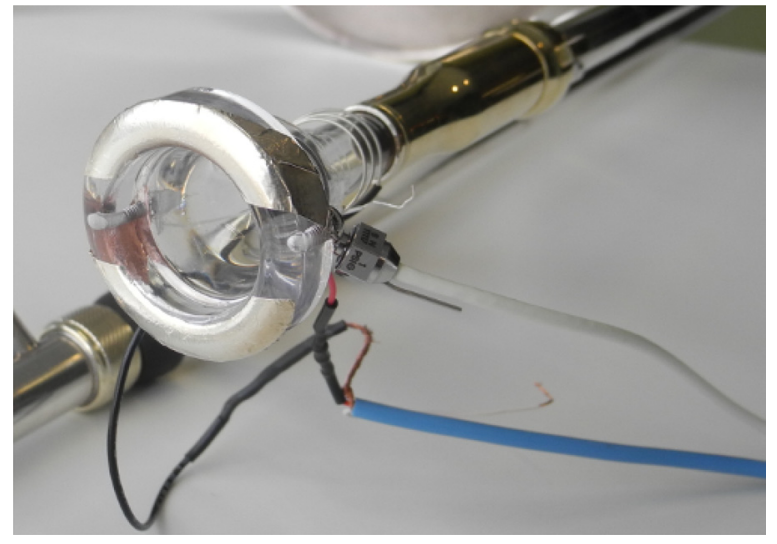

FIG. 1. (Color online) Kelly plastic mouthpiece 6 1/2 AL with two silverplated electrodes mounted on the rim. The downstream microphone is mounted to record the acoustic pressure in the mouthpiece cup.

system (delay between actual variations of lip impedance and the output tension from the conditioner), a controllable variable resistance was mounted at the electrodes using a photo field effect transistor optocoupler. This calibration procedure enabled estimation of a group delay of $180 \mu \mathrm{s}$. Considering a sampling rate of $44.1 \mathrm{kHz}$, this latency results in a shift of eight samples which is not negligible in the context of phase analysis and is therefore taken into account in the analysis. The electrolabiograph signal, as well as $P_{d}$ and $P_{u}$ were recorded using a National Instruments I/O interface (sampling rate $44.1 \mathrm{kHz}$ ). After correction of the latency of the elctrolabiograph signal conditioner, $\angle G_{d}\left(f_{0}\right), \angle G_{u}\left(f_{0}\right)-\pi$, and $\angle G\left(f_{0}\right)$ are computed by extracting the phase at the $f_{0}$ spectral peak from consecutive fast Fourier transforms of 1024 samples with an overlap of 256 or 512 samples depending on the playing task. Zero-padding was performed prior to Fourier transforming in order to increase the frequency resolution of computed spectra and refine the phase estimation at $f_{0}$.

\section{Interpretation of the data}

For convenience, we adopt the following notation: $\angle G_{d}=\angle G_{d}\left(f_{0}\right), \angle G_{u-\pi}=\angle G_{u}\left(f_{0}\right)-\pi$ and $\angle G=\angle G\left(f_{0}\right)$. It is worth noting that from the definitions of $G_{d}$ and $G_{u}$, the following relations can be deduced:

$$
\angle G_{d}-\angle G_{u-\pi}=\angle P_{u}-\angle P_{d}+\pi=\angle Z_{u}-\angle Z_{d}
$$

and, as described in the Appendix:

$$
\frac{\left|\angle G_{d}-\angle G\right|}{\left|\angle G_{u-\pi}-\angle G\right|}=\frac{\left|\angle\left(P_{d}-P_{u}\right)-\angle P_{d}\right|}{\left|\angle\left(P_{d}-P_{u}\right)-\angle P_{u}-\pi\right|} \simeq\left|\frac{Z_{u}}{Z_{d}}\right|
$$

when $\angle G_{d}\left(f_{0}\right)-\angle G_{u-\pi}\left(f_{0}\right)$ is relatively close to zero (see the Appendix for further clarification on this limitation).

Graphically, Eq. (10) indicates that the distance between $\angle G_{d}$ and $\angle G_{u-\pi}$ gives a representation of the distance between $\angle Z_{d}$ and $\angle Z_{u}$ at $f_{0}$. Second, Eq. (11) reveals that the relative position between $\angle G, \angle G_{d}$, and $\angle G_{u-\pi}$ is related to the relative acoustical coupling between the lips, the downstream air-column, and the vocal-tract; if the distance between $\angle G$ and $\angle G_{d}$ is smaller than the distance between $\angle G$ and $\angle G_{u-\pi}$, this indicates a predominant coupling with the downstream system at $f_{0}$, and vice versa. When $\angle G$ is equally spaced from $\angle G_{d}$ and $\angle G_{u-\pi}$, then both systems provide equal support to lip auto-oscillations.

Overall, our analysis scheme allows to combine timedomain visualizations of three attributes of the regenerative processes at the fundamental frequency of the sound: (1) the dominant regenerative system via the relative amplitude of $P_{d}$ and $P_{u}$ [see Eq. (1)], as well as relative proximities of $\angle G_{d}, \angle G_{u-\pi}$, and $\angle G$, as defined by Eq. (11); (2) the degree of "phase tuning" of upstream and downstream systems at the playing frequency via the phase difference between $Z_{d}$ and $Z_{u}$, as defined by Eq. (10); and (3) an estimate of $\angle Z_{d}$, $\angle Z_{u}$, and $\angle Z$ via the values of $\angle G_{d}, \angle G_{u-\pi}$, and $\angle G$ [see Eqs. (7), (8), and (9)].

\section{Player tests}

Nine subjects took part in the experiments. Two of them are professional players performing in high level Canadian ensembles and teaching trombone at the Schulich School of Music at McGill University, five are young professional players who perform in classical and jazz ensembles in Montreal, one is an undergraduate student in jazz performance and one is an experienced trombone player and also first author of this article. All measurements were performed on the same tenor trombone (King 2B Silver Sonic) and same mouthpiece (Kelly 6 1/2 AL) on which the downstream microphone and electrolabiograph electrodes were mounted. The tuning slide was kept closed and subjects asked to avoid compensating for possible detuning of the instrument (which resulted in playing frequencies slightly above a $440 \mathrm{~Hz}$ reference). Participants were given some time to get accustomed to the trombone and mouthpiece setup prior to measurements. The amplitude and phase of the acoustical input impedance of the trombone and mouthpiece with the slide in the closed position are given in Fig. 2. The input impedance was measured using a two-microphone impedance measurement system. ${ }^{39}$

A real-time display of the electrolabiograph (ELG) waveform was provided to the subjects so they could identify when the lip impedance measurement was working or not; for some players, the electrodes needed to be humidified quite often to enable optimum electrical conduction. Subjects were presented each task prior to execution. Each task was recorded several times until the subjects were satisfied with their performance. At the end of the session, participants were asked to fill out a questionnaire about their trombone performance background and experience. After experiments, all recordings were reviewed by the experimenter. For each subject, the best execution of each task was selected for analysis, based on the sound and ELG signal quality.

\section{RESULTS}

\section{A. Arpeggios}

The first task involved playing ascending and descending arpeggios in closed position from F3 $(175 \mathrm{~Hz})$ to $\mathrm{F} 5$ 


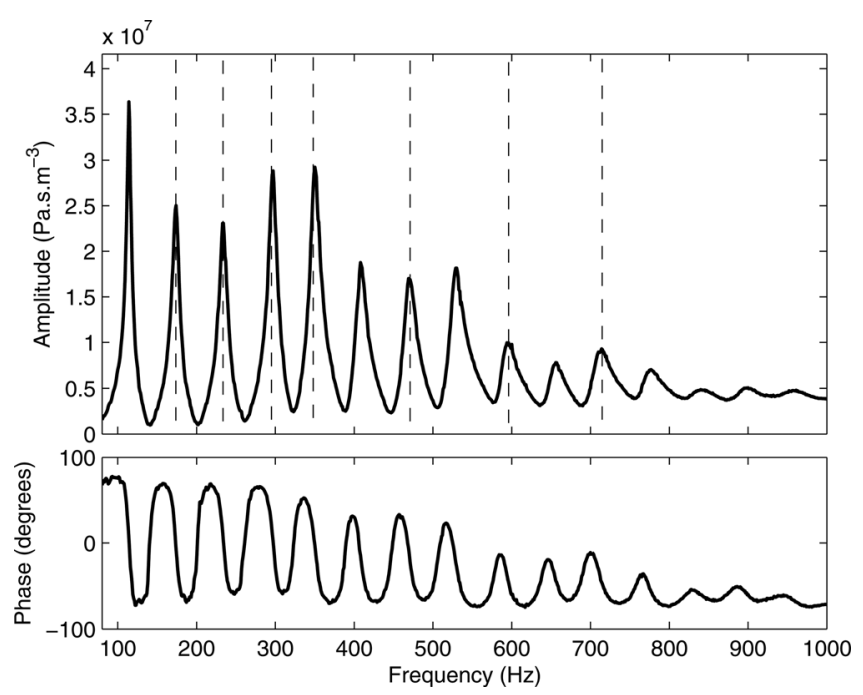

FIG. 2. Amplitude and phase of the input impedance of the King 2B Silver Sonic tenor trombone and Kelly $61 / 2$ AL mouthpiece with the slide in the closed position (the first resonance located below $80 \mathrm{~Hz}$ is not measured). Vertical dashed lines indicate the resonances corresponding to the arpeggio series F3-Bb3-D4-F4-Bb4-D5-F5.

$(710 \mathrm{~Hz}),{ }^{40}$ corresponding to the following tone sequence F3-Bb3-D4-F4-Bb4-D5-F5. The subjects were asked to slur the tone series (no tonguing articulation between tones). As a first example of collected data, results obtained from Subject A are presented in Fig. 3. Starting from the top of the figure, the first plot represents $p_{d}$ and $p_{u}$ waveforms normalized by the $p_{d}$ maximum, the second represents the temporal evolution of $\angle G_{d}, \angle G_{u-\pi}$, and $\angle G$ at $f_{0}$, the third plot
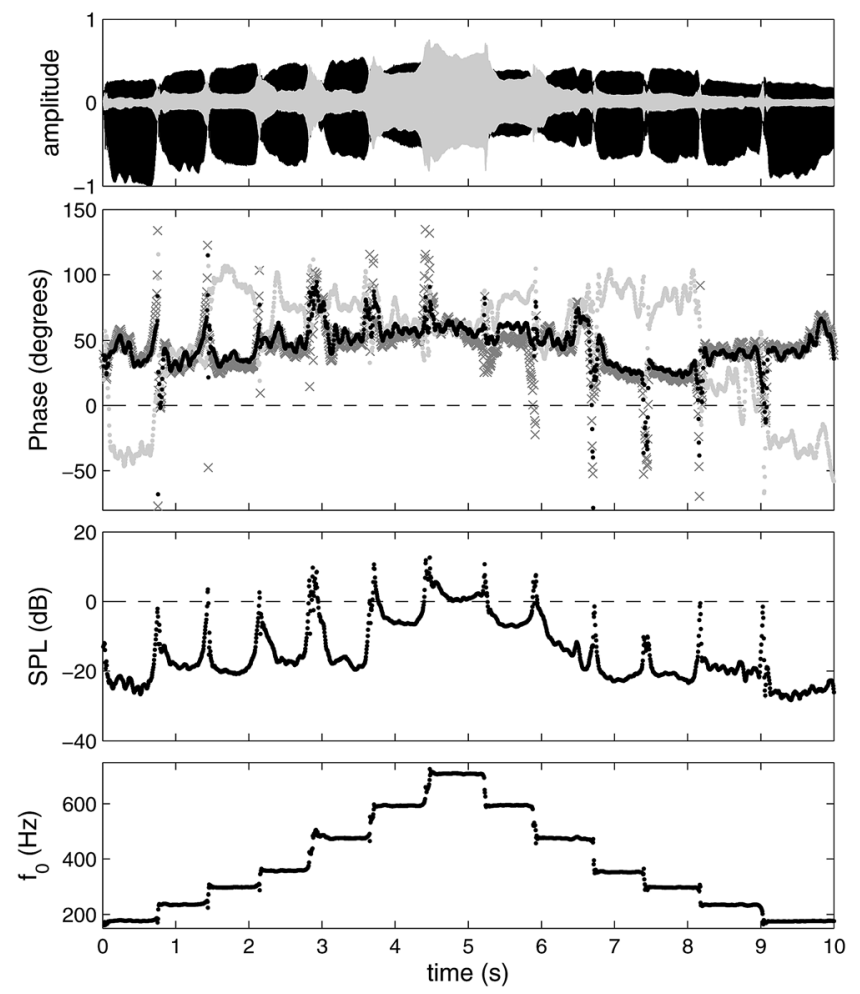

FIG. 3. Subject A playing ascending and descending arpeggio series: F3Bb3-D4-F4-Bb4 -D5-F5. From top to bottom: waveforms of $p_{d}$ (black), $p_{u}$ (gray); $\angle G_{d}$ (dark gray), $\angle G_{u-\pi}$ (light gray), and $\angle G$ (black) at $f_{0}$; SPL ratio in $\mathrm{dB}$ of the upstream to downstream pressure; fundamental frequency. represents the evolution of the sound pressure level (SPL) ratio $\left|P_{u} / P_{d}\right|$ in $\mathrm{dB}$ at $f_{0}$, and the bottom plot the evolution of fundamental frequency $f_{0}$ as a function of time.

During the sustained portions of the ascending tone series, the ratio $\left|P_{u} / P_{d}\right|$ remains low (around $-20 \mathrm{~dB}$ ) until $\mathrm{B} b 4(475 \mathrm{~Hz})$. It then reaches a maximum value around $0 \mathrm{~dB}$ at the highest tone F5 $(710 \mathrm{~Hz})$. Furthermore, tone transitions and onsets are marked by abrupt variations of $\left|P_{u} / P_{d}\right|$ with peak values around $10 \mathrm{~dB}$ at the onset of the three highest tones, this effect being less noticeable in the descending arpeggio portion. These first observations show that for the two highest tones, the input impedance of the upstream airways at $f_{0}$ becomes close to the magnitude of the downstream input impedance, suggesting a strategic vocal-tract tuning by the player in the high register. The peaks in the $\left|P_{u} / P_{d}\right|$ trace at tone transitions also suggest a possible upstream tuning at slurred transitions between tone registers. Although the characteristics of the volume flow at regime shifts between two tones may significantly deviate from a quasi-static Bernoulli flow model, the duration of these $\left|P_{u} / P_{d}\right|$ peaks (above $100 \mathrm{~ms}$ ) suggest that an increase in $\left|P_{u} / P_{d}\right|$ occurs before and after the frequency shift during a time when steady-state oscillations are established. This potentially indicates occurrences of vocal-tract support at tone transitions. This is further discussed in Sec. IVID of this article.

Although $\angle G_{d}$ and $\angle G$ remain quite stable during the task, significant variations of $\angle G_{u-\pi}$ are observed, from $-50^{\circ}$ at F3 $(175 \mathrm{~Hz})$ to $100^{\circ}$ at D4 $(295 \mathrm{~Hz})$ and F4 $(360 \mathrm{~Hz})$. No strong hysteresis behavior is observed between the ascending and descending portions. The negative value of $\angle G_{u-\pi}$ at $\mathrm{F} 3(175 \mathrm{~Hz})$ suggests a positive value of $\angle Z_{u}$ and therefore an inductive upstream impedance at $f_{0}$. However, all the other tones show a positive value of $\angle G_{u-\pi}$ and thus a capacitive upstream coupling. On the contrary, $\angle G_{d}$ remains positive for all tones indicating a capacitive downstream impedance at $f_{0} . \angle G$ seems to overlap with $\angle G_{d}$ for all notes and with $\angle G_{u-\pi}$ as well for the two highest tones, which is corroborated by the high SPL value of $\left|P_{u} / P_{d}\right|$ observed for these two tones. Therefore, the low register is characterized by a dominant downstream coupling, as well as relatively high distance between $\angle Z_{d}$ and $\angle Z_{u}$. An increase in pitch seems to correlate with an increase in $\left|P_{u} / P_{d}\right|$ as well as a decrease in the distance between $\angle Z_{d}$ and $\angle Z_{u}$, suggesting a constructive phase tuning of the downstream and upstream systems at $f_{0}$ in the higher register.

Figure 4 presents results obtained for different participants during the ascending part of the arpeggio series. The left column displays the data from Subject A and Subject C. Subject $\mathrm{C}$ shows increasing values of $\left|P_{u} / P_{d}\right|$ with increase in pitch and a maximum value at Eb5 (not played by Subject A). The values of $\left|P_{u} / P_{d}\right|$ at D5 $(595 \mathrm{~Hz})$ and F5 $(710 \mathrm{~Hz})$ are about the same in both subjects. Analogously to Subject A, the same transitory peak variations of the ratio are observed in Subject C. In both subjects, the abrupt sign change of $\angle G_{u-\pi}$ between the two first tones is observed. Although $\angle G_{u-\pi}$ stays greater than $\angle G_{d}$ in Subject A, it becomes smaller than $\angle G_{d}$ while remaining positive in Subject $\mathrm{C}$ from the 5 th tone. As in Subject A, $\angle G$ follows the variations of $\angle G_{d}$ in Subject $C$, except for the last and 
highest tone where $\angle G$ lies in between $\angle G_{d}$ and $\angle G_{u-\pi}$. We observe that $\angle G_{d}$ shows more variability in Subject $\mathrm{C}$ while $\angle G_{d}$ and $\angle G_{u-\pi}$ are smoothly converging toward the same value with increase in pitch in Subject A.

The right column of Fig. 4 displays the data from Subject B and Subject D. In both subjects $\left|P_{u} / P_{d}\right|$ values are higher than Subjects $A$ and $C$ in the high register with less pronounced peaks at tone transitions. Subject B shows a change in the sign of $\angle G_{u-\pi}$ at the third tone while $\angle G_{u-\pi}$ stays negative along the entire ascending series for Subject D. In both subjects, $\angle G$ tends to decrease with increase in pitch, as opposed to the tendency observed in Subjects A and C. This trend is even more pronounced in Subject D. In Subject A, $\angle G$ and $\angle G_{d}$ overlap until the two last tones while in Subject $\mathrm{D}, \angle G$ smoothly moves from $\angle G_{d}$ to $\angle G_{u-\pi}$ as the pitch increases. No clear constructive phase tuning of $Z_{d}$ and $Z_{u}$ is therefore observed in Subject B and D. Although $\angle G_{d}$ remains positive in both subjects for the entire task, it shows quite unstable behavior at the highest tones.

In order to compare experimental results from all the subjects, all extracted variables are averaged over stable sections of each tone. For each subject, stable portions are extracted based on fundamental frequency standard deviation criteria; for a given playing frequency $f_{0}$, a section of the tone is considered stable if the standard deviation of $f_{0}$ is below a threshold of $4 \mathrm{~Hz}$ within the observation window. Using this approach, values of $\left|P_{u} / P_{d}\right|,\left|P_{d}\right|,\left|P_{u}\right|, p_{0}, \angle G_{d}, \angle G_{u-\pi}$, and $\angle G$ are extracted for each tone of the arpeggio series and for each subject.

Figure 5 represents the SPL ratio $\left|P_{u} / P_{d}\right|$ in $\mathrm{dB}$, as well as dimensionless variables $\gamma_{d}=\left|P_{d}\left(f_{0}\right)\right| / p_{0}$ and $\gamma_{u}=$ $\left|P_{u}\left(f_{0}\right)\right| / p_{0}$ for all subjects and for each tone of the ascending arpeggio series (1:F3, 2: Bb3, 3:D4, 4:F4, 5: Bb4, 6:D5, $7: F 5)$. While all the subjects were able to play the ascending tone sequence until $\mathrm{B} b 4$, only the first six subjects were able to play up to D5 $(595 \mathrm{~Hz})$ and only the first five subjects were able to play up to F5 $(710 \mathrm{~Hz})$. If we assume that the amplitude of $Z_{d}$ at $f_{0}$ does not differ significantly between subjects despite some small differences in individual playing frequencies, we can reasonably assume that the dimensionless parameter $\gamma_{d}$ provides a representation of the mechanical ability of the lips to respond to the static blowing pressure. We therefore use this variable as a descriptor of what can be referred to as the "lip mechanical efficiency."

The low register is marked by negative values of $\left|P_{u} / P_{d}\right|$ SPL suggesting a predominant influence of the downstream
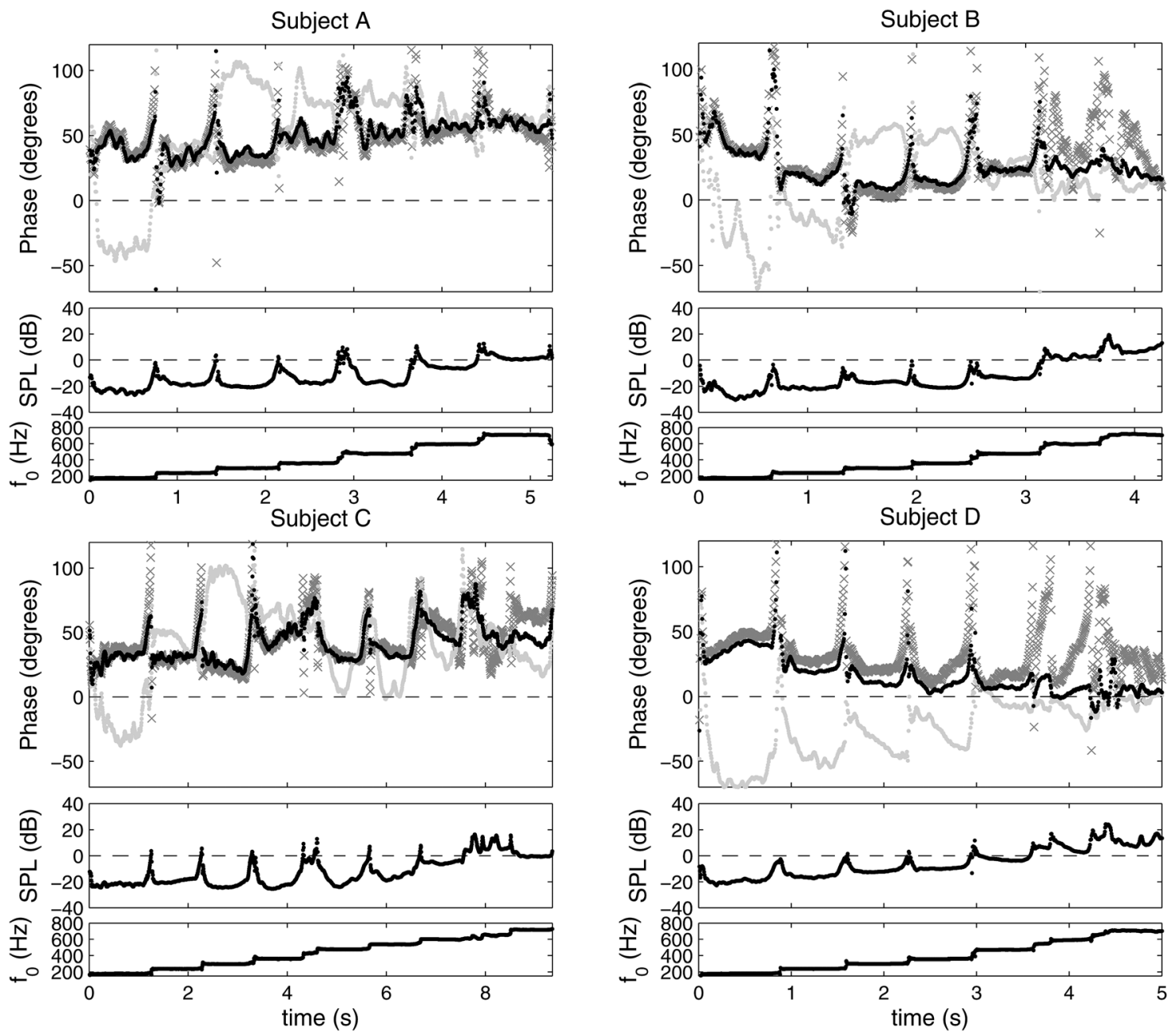

FIG. 4. Subjects A, B, C and D playing ascending arpeggio series F3-Bb3 -D4-F4-Bb4-D5-F5. From top to bottom: $\angle G_{d}$ (dark gray), $\angle G_{u-\pi}$ (light gray), and $\angle G$ (black) at $f_{0}$; SPL ratio in $\mathrm{dB}$ of the upstream to downstream pressure; fundamental frequency. Note that Subject $\mathrm{C}$ played additional overtones [C5 $(535 \mathrm{~Hz})$ and $\mathrm{Eb} 5(640 \mathrm{~Hz})]$ in the tone series. 

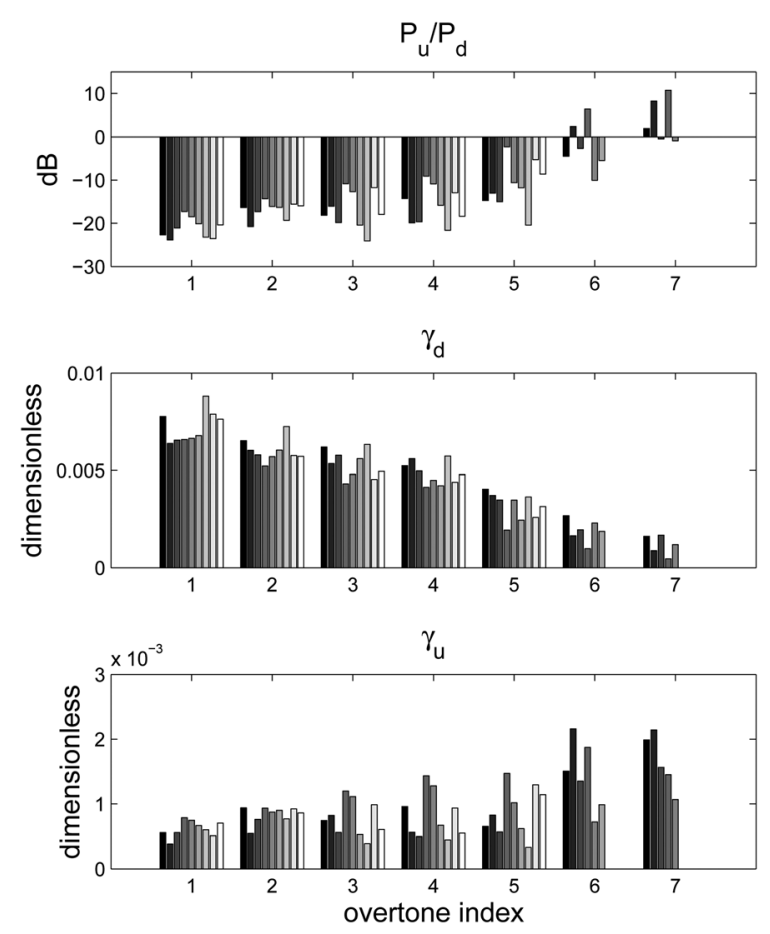

FIG. 5. SPL ratio in $\mathrm{dB}$ of upstream to downstream pressure at $f_{0}$, downstream and upstream pressure magnitude at $f_{0}$ normalized to the quasi-static blowing mouth pressure as a function of arpeggio index for all subjects (index refers to the ascending series F3-B b3-D4-F4-Bb4-D5-F5).

air-column. A clear change is observed at D5 $(595 \mathrm{~Hz})$ where Subjects B and D show positive SPL ratios indicating a predominant coupling with the vocal tract at the playing frequency. This tendency is confirmed by negative but small values of the SPL ratio in other subjects at D5 $(595 \mathrm{~Hz})$. At F5 $(710 \mathrm{~Hz})$, Subjects A, B, and D exhibit positive SPL ratios whereas Subjects $\mathrm{C}$ and $\mathrm{E}$ show ratios close to zero. This suggests a significant influence of upstream impedance in all subjects. $\gamma_{d}$ values decrease with increasing playing frequency, which correlates with a decrease in $Z_{d}$ amplitude with frequency in brass instruments (as $\left|Z_{d}\right|$ decreases, downstream support becomes weaker and more energy is needed to maintain lip oscillations). However, the opposite behavior is observed in $\gamma_{u}$, supporting the hypothesis of a growing amplitude of $Z_{u}$ at $f_{0}$ with increase in pitch.

Estimation of $\angle Z_{d}\left(f_{0}\right), \angle Z_{u}\left(f_{0}\right)$, and $\angle Z\left(f_{0}\right)$ from lip mobility measurements are represented in Fig. 6. $\angle Z_{d}\left(f_{0}\right)$ remains negative for all subjects suggesting a compliant downstream input impedance at $f_{0}$ along the task. $\angle Z_{u}\left(f_{0}\right)$ is positive for all subjects at $\mathrm{F} 3(175 \mathrm{~Hz})$ supporting an inductive upstream impedance at $f_{0}$ for the lowest tone. At $\mathrm{B} b 3$ ( $235 \mathrm{~Hz}$ ), four subjects show a positive $\angle Z_{u}\left(f_{0}\right)$. Only Subject D maintains a positive or null $\angle Z_{u}\left(f_{0}\right)$ value for all tones with $\angle Z_{u}\left(f_{0}\right) \simeq 0^{\circ}$ at $\mathrm{F} 5(710 \mathrm{~Hz})$. Above $\mathrm{Bb} 3(235 \mathrm{~Hz})$, all other subjects show negative values of $\angle Z_{u}\left(f_{0}\right)$, except Subject $\mathrm{G}$ who shows a positive value at $\mathrm{B} b 4(475 \mathrm{~Hz})$. These observations suggest a dominant inductive effect of players' vocaltract in the low register with a rapid transition to a capacitive upstream coupling with increase in pitch.

Regarding the total impedance applied to the lips, $\angle Z\left(f_{0}\right)$ remains negative for all tones. Inter-subject variability grows with increase in pitch; Subject A shows the smallest
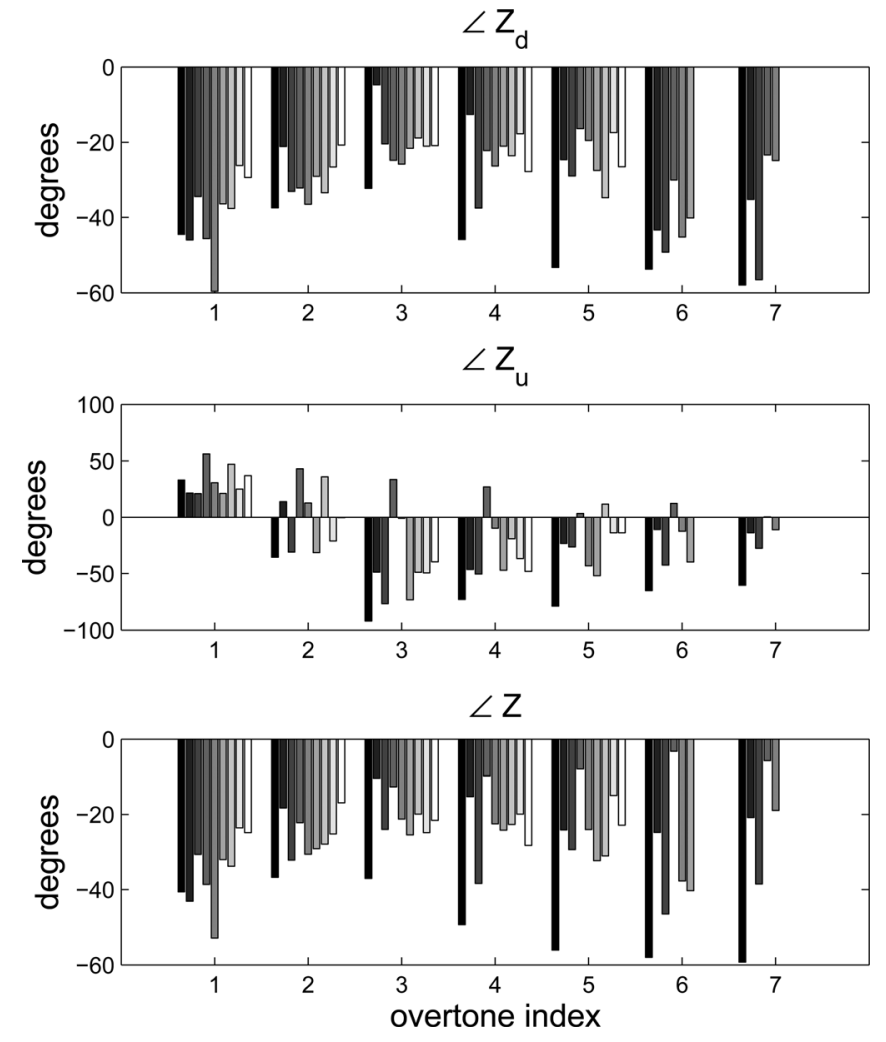

FIG. 6. Estimated $\angle Z_{d}, \angle Z_{u}$, and $\angle Z$ at $f_{0}$ as a function of arpeggio index for all subjects (index refers to the ascending series F3-Bb3-D4-F4-Bb4-D5-F5).

values around $-60^{\circ}$ for the three highest tones, while Subject $\mathrm{D}$ shows the greatest values between $-8^{\circ}$ for $\mathrm{B} b 4$ $(475 \mathrm{~Hz})$ and $-3^{\circ}$ at F5 $(710 \mathrm{~Hz})$.

As vocal-tract adjustments appear to occur at high playing frequencies, we now focus our attention on the three highest tones of the arpeggio series. Looking particularly at $\left|P_{u} / P_{d}\right|, \gamma_{d}$, and $\gamma_{u}$ for D5 $(595 \mathrm{~Hz})$ and F5 $(710 \mathrm{~Hz})$, we observe that Subjects B and D display the higher values of the SPL ratio and lower values of $\gamma_{d}$, indicating that although these two players were able to create high magnitude upstream impedances at $f_{0}$, the mechanical efficiency of the lips estimated from the dimensionless parameter $\gamma_{d}$ remained low compared to other subjects. This correlation does not apply to $\gamma_{u}$; while the amplitude of $Z_{d}$ is about the same for all subjects at the playing frequency, the magnitude of $Z_{u}$ at $f_{0}$ significantly differs for each subject as shown by differences in $\left|P_{u} / P_{d}\right|$ (high for Subjects B and D, and lower for the others).

Subjects $\mathrm{A}$ and $\mathrm{C}$ show lower values of $\angle Z_{d}$ and $\angle Z_{u}$ than Subjects B and D. This may indicate that Subjects A and $\mathrm{C}$ were able to create an upstream resonance centered at a lower frequency than Subjects B and D, allowing oscillations to occur at a lower value of $\angle Z_{d}$. This tuning strategy results in a lower value of $\angle Z$ which means a value of $\angle G$ close to $90^{\circ}$. Therefore, if we assume that the lips oscillate according to an outward striking regime, one may hypothesize that the tuning strategy for Subjects A and C favors lip oscillations near a mechanical resonance of the lips. We thus distinguish two strategies: (1) strategy of Subjects B and D: high amplitude upstream resonance at $f_{0}$ overriding the downstream regenerative influence, and (2) strategy of Subject A and C: 
careful tuning of $Z_{u}$ phase at $f_{0}$ which might better support oscillations near a mechanical resonance of the lips.

Nevertheless, Subject E does not fit clearly in either of the two categories, especially for the highest tone F5 $(710 \mathrm{~Hz})$. Indeed, although this subject exhibits values of $\angle Z_{d}, \angle Z_{u}$, and $\angle Z_{u}$ similar to Subjects B and D at F5 $(710 \mathrm{~Hz})$, Subject E shows a slightly negative $\left|P_{u} / P_{d}\right|$ ratio and relatively high $\gamma_{d}$ at this playing frequency, as in Subjects A and B.

In order to evaluate whether the observed increase in $\left|P_{u} / P_{d}\right|$ with $f_{0}$ results from an actual tuning of the vocaltract or the overall reduction in the magnitude of $Z_{d}$ resonances with increase in frequency, the value of $Z_{u}$ is estimated from Eq. (1) at the fundamental frequency and first few harmonics for each tone of the ascending arpeggio series. It is then possible to characterize the evolution of $\left|Z_{u}\right|$ at particular frequencies appearing in the harmonic structure of specific tones. For instance, the frequency of the first harmonic of $\mathrm{B} b 3$ located around $475 \mathrm{HZ}$ corresponds to the fundamental frequency of $\mathrm{B} b 4(475 \mathrm{~Hz})$. Consequently, the magnitude of $Z_{u}$ around $475 \mathrm{~Hz}$ can be calculated at these two steps of the arpeggio sequence and potential changes in $\left|Z_{u}\right|$ identified. The evolution of $Z_{u}$ magnitude at 475,595 , and $710 \mathrm{~Hz}$ as a function of $f_{0}$ is presented in Fig. 7 during ascending arpeggios for the subjects able to play up to D5 $(595 \mathrm{~Hz})$ (Subjects A-F).
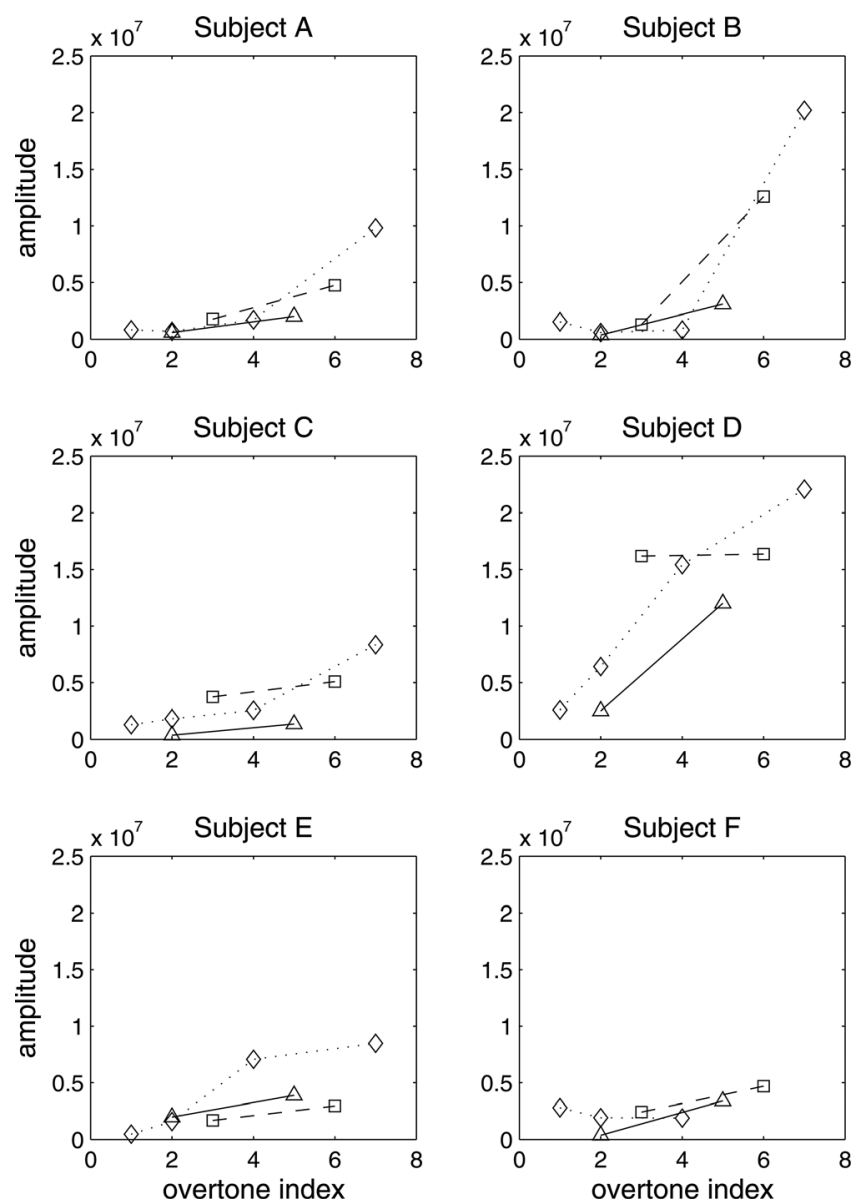

FIG. 7. Evolution of the magnitude of the upstream input impedance at frequencies of a Bb3 $(475 \mathrm{~Hz})$ (triangle solid line), D5 $(595 \mathrm{~Hz})$ (square dashed line) and F5 $(710 \mathrm{~Hz})$ (diamond dotted line) as a function of overtone index during ascending arpeggios for Subjects A to F.
In all subjects able to play over the full range (subjects A-E), the amplitude of $Z_{u}$ around $710 \mathrm{~Hz}$ increases with increase in pitch, supporting the hypothesis of a tuning of the vocal tract in the higher register. Subject B shows significant variations in $\left|Z_{u}\right|$ around $595 \mathrm{~Hz}$ between overtone 3 (D4) and 6 (D5), while Subject $C$ presents a constant but high amplitude of $Z_{u}$ at $595 \mathrm{~Hz}$ and an increase in $Z_{u}$ amplitude at $475 \mathrm{~Hz}$ between overtones $2(\mathrm{~B} b 3$ at $235 \mathrm{~Hz})$ and $5(\mathrm{~B} b 4$ at $475 \mathrm{~Hz}$ ). Moreover, in agreement with the categorization proposed, Subjects A and C show similar tuning patterns for the three frequencies observed, while subjects B and D show the highest values of $\left|Z_{u}\right|$ at both 475 and $595 \mathrm{~Hz}$. Subject E presents a tuning trend closer to subjects $\mathrm{A}$ and $\mathrm{C}$, although this subject is the only one showing a lower magnitude of $Z_{u}$ at $595 \mathrm{~Hz}$. Finally, Subject F does not present any significant tuning pattern and could not play the highest tone.

\section{B. Influence of dynamics}

In order to evaluate the influence of loudness on the characteristics of an upstream coupling, subjects were asked to play a sustained $\mathrm{B} b 4(475 \mathrm{~Hz})$ from mezzo-piano $(\mathrm{mp})$, crescendo to the maximum loudness they could comfortably reach and decrescendo to mezzo-piano. The choice of $\mathrm{B} b 4$ was made since it is high enough to induce significant vocaltract support and low enough to allow a clear crescendo and decrescendo to be produced comfortably. We propose a representation where $\angle G_{d}$ and $\angle G_{u-\pi}$ values are mapped onto a color scale extending from $-30^{\circ}$ to $140^{\circ}$ and hence centered around $85^{\circ}$. According to this color scale, dark tonalities will be associated to a capacitive impedance whereas light tonalities will rather suggest an inductive input impedance. The boundary between the color arrays of $\angle G_{d}$ and $\angle G_{u-\pi}$ correspond to the SPL value of $\left|P_{u} / P_{d}\right|$ in $\mathrm{dB}$. Results from Subjects A, B, C, D, E, and G are presented in Fig. 8. Results from other subjects showing a smaller crescendo-decrescendo effect are not shown. The top color area corresponds to $\angle G_{d}$ while the bottom area corresponds to $\angle G_{u-\pi}$. The black dashed lines represents the amplitude of $P_{d}\left(f_{0}\right)$ (considered as an index of loudness).

All subjects show a negative SPL ratio along the tone duration, indicating a predominant coupling with the downstream air-column. In all subjects, $\left|P_{u} / P_{d}\right|$ varies significantly with variations in $P_{d}$ amplitude. All subjects, except $\mathrm{B}$, show a maximum in $P_{d}$ fitting with a minimum in SPL ratio. In Subject B, both extrema do not exactly match although the SPL ratio shows a low-value plateau around the peak of downstream energy. The lowest minimum value of the SPL ratio is found in Subject C around $-40 \mathrm{~dB}$ whereas Subject D shows a minimum at $-14 \mathrm{~dB}$. The greatest variations of SPL ratio are observed in Subjects B, C, and G, for which higher dynamics are associated with a plateau of low SPL ratio. This phenomenon is not as visible in Subjects A, D, and E.

From color area observations, we notice that $\angle G_{d}$ remains relatively constant along tone duration for all subjects compared to variations in $\angle G_{u-\pi}$. The values of $\angle G_{d}$ are quite similar in all subjects (between 20 and $60^{\circ}$ ) suggesting a capacitive downstream input impedance at $f_{0}$. $\angle G_{u-\pi}$ remains positive and constant in Subjects $\mathrm{A}$ and $\mathrm{E}$ 

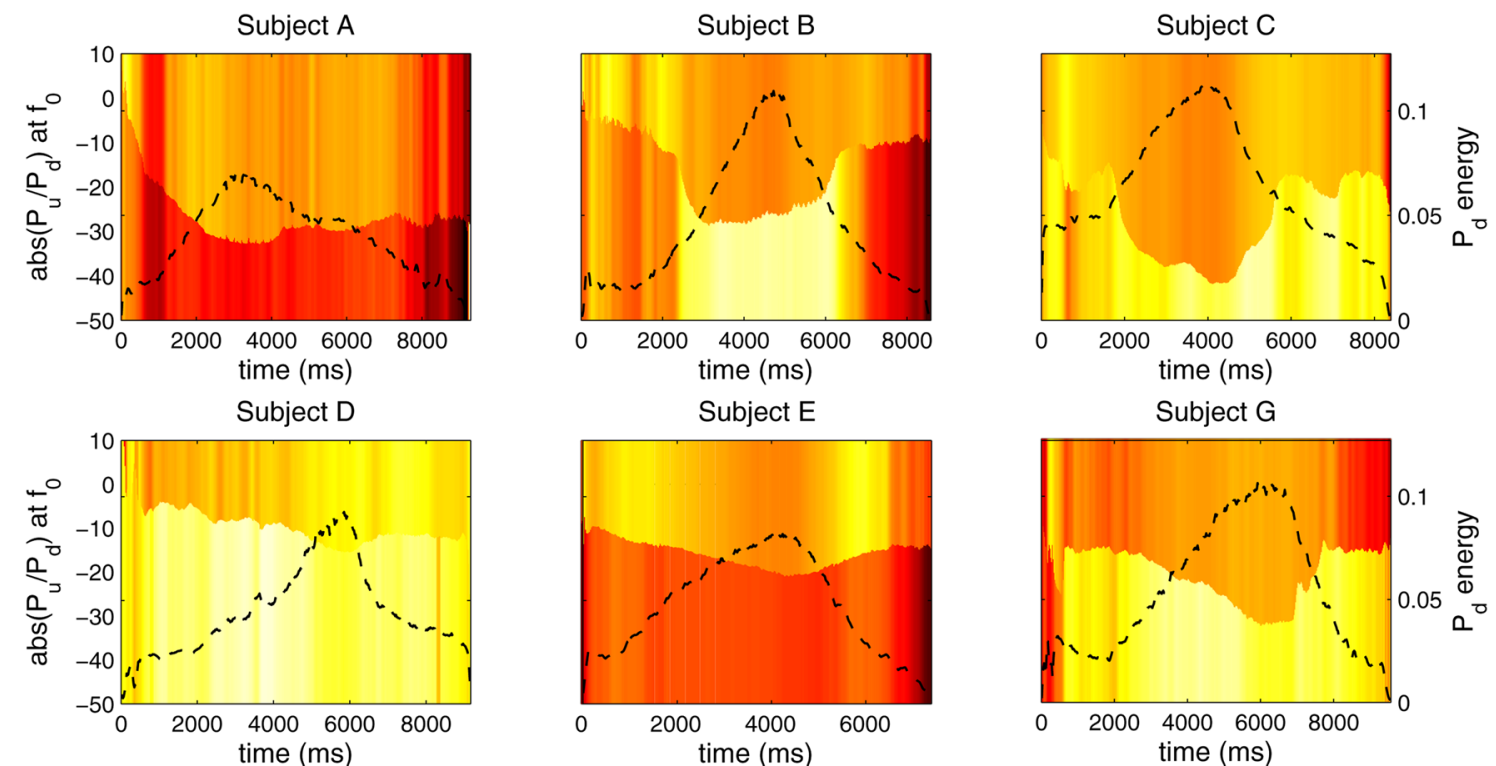

Subject $\mathrm{E}$
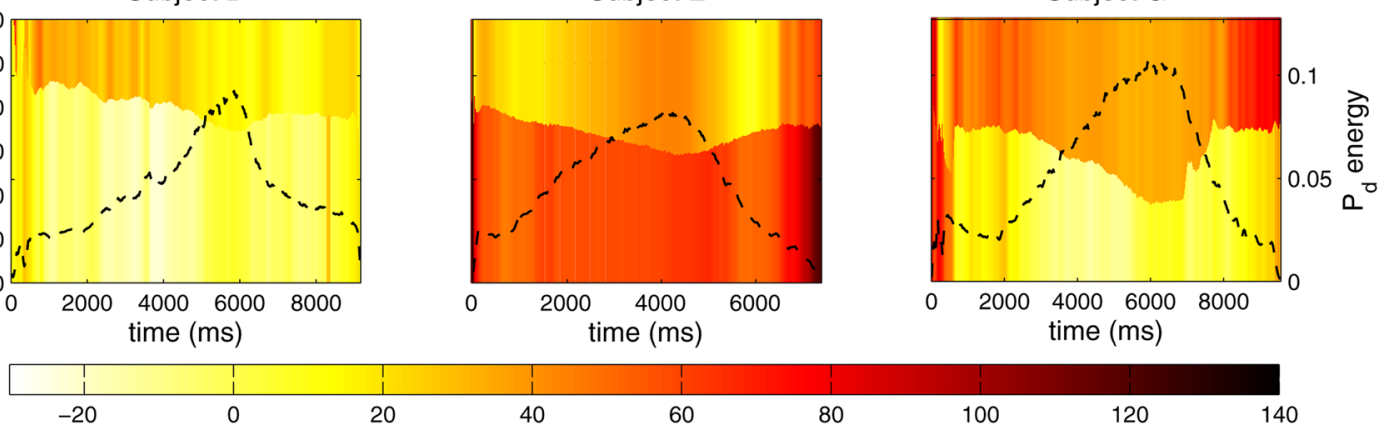

FIG. 8. (Color online) SPL ratio in $\mathrm{dB}$ of the upstream to downstream pressure (boundary between color areas), $\angle G_{d}$ (top color area), $\angle G_{u-\pi}$ (bottom color area), $P_{d}$ amplitude (dashed black line) during sustained Bb4 (475 Hz) played following a crescendo-decrescendo dynamic pattern for Subjects A, B, C, D, E, and G. Color scale unit: degrees.

which supports a capacitive vocal-tract impedance along the tone duration. Analogously, $\angle G_{u-\pi}$ remains stable but closer to zero in Subjects $D$ and $G$ suggesting an inductive upstream impedance. More variability in the $\angle G_{u-\pi}$ value is observed in Subject B; Subject C shows small oscillations of $\angle G_{u-\pi}$ along the task while Subject B displays a clear change in $\angle G_{u-\pi}$ around the $\left|P_{d}\right|$ peak value. For this player, vocal-tract impedance varies from a capacitive to an inductive character and the value of $\angle G_{u-\pi}$ seems well correlated with variations in SPL ratio. To a lesser extent, variations of $\angle G_{u-\pi}$ around the minimum of $\left|P_{u} / P_{d}\right|$ are also observed in Subjects C, D, G, and somewhat in E, where a smooth variation of both $\angle G_{d}$ and $\angle G_{u-\pi}$ accompanies variations of loudness and playing frequency.

Overall, these observations suggest two categories of behavior: (1) a marked decrease in SPL ratio correlated with increase in dynamic, possibly associated with variations in $\angle G_{u-\pi}$ caused by changes in vocal-tract shape, and (2) rather stable upstream impedance, in amplitude and phase, with less marked minimum in SPL ratio at the downstream pressure peak. However, for high amplitude oscillations (as must be the case at the maximum loudness), it is difficult to formulate strong conclusions regarding the nature of $\angle Z_{d}$ and $\angle Z_{u}$ within the linear theory of oscillation.

\section{Pitch bending}

Although pitch bends are easy to produce on trombones by simply varying the slide length while maintaining a constant blowing condition, bent tones may also be produced by forcing lip oscillations below the frequency of a well sustained tone for a given slide position. This maneuver may be used in order to play, for instance, an Eb2 $(77 \mathrm{~Hz})$ at the 7th position of the slide for which the second input impedance peak is located at the frequency of an E2 $(82 \mathrm{~Hz})$. It therefore requires the player to maintain lip oscillations at a frequency not well supported by the downstream air-column. In contrast to woodwind playing, a brass player has a direct control on the mechanical resonance of the lips and may force oscillations away from a resonance of the air-column. ${ }^{24,28}$ However, one may also hypothesize that players are capable of producing a significant vocal-tract resonance in the neighborhood of the playing frequency to support lip oscillations during a pitch bend.

In order to investigate this hypothesis, subjects were asked to perform a slow pitch bend starting from a $\mathrm{B} b 2$ at $120 \mathrm{~Hz}$ (in closed position of the slide) to the lowest frequency they could maintain, and then back up to $B b 2$. Results from Subjects A, B, and D (who performed the largest bends) are represented in Fig. 9. The frequency range covered by the three subjects is quite identical and extends from 122 to $85 \mathrm{~Hz}$ for Subject A, from 122 to $87 \mathrm{~Hz}$ for Subject B, and from 122 to $93 \mathrm{~Hz}$ for Subject D. Subjects A and $B$ were thus able to bend down to the frequency of an F2 around $90 \mathrm{~Hz}$ (a 4th below B b2), while Subject D bent down to an $\mathrm{F} 2 \sharp$ around $95 \mathrm{~Hz}$ (a major 3rd below $\mathrm{B} b 2$ ).

In addition the value of $\left|Z_{u}\right|$ at $f_{0}$ is estimated for each subject during the task using Eq. (1) and presented in Fig. 9. In the three subjects, an increase of the ratio $\left|P_{u} / P_{d}\right|$ at $f_{0}$ is observed when bending down, but this increase seems to be due to the deflection of $\left|Z_{d}\right|$ at $f_{0}$ when the pitch is decreased, while $Z_{u}$ remains constant. Peak values of the ratio are observed around $-4 \mathrm{~dB}$ in Subject $\mathrm{D},-14 \mathrm{~dB}$ in Subject $B$ and $-16 \mathrm{~dB}$ in Subject A. This variation in vocal-tract support occurs simultaneously with important alterations of $\angle G_{u-\pi}: \Delta \angle G_{u-\pi}=130^{\circ}$ in Subject $\mathrm{A}$, $\Delta \angle G_{u-\pi}=110^{\circ}$ in Subject $\mathrm{B}$, and $\Delta \angle G_{u-\pi}=110^{\circ}$ in Subject D. On the contrary, $\angle G_{d}$ remains more stable in 

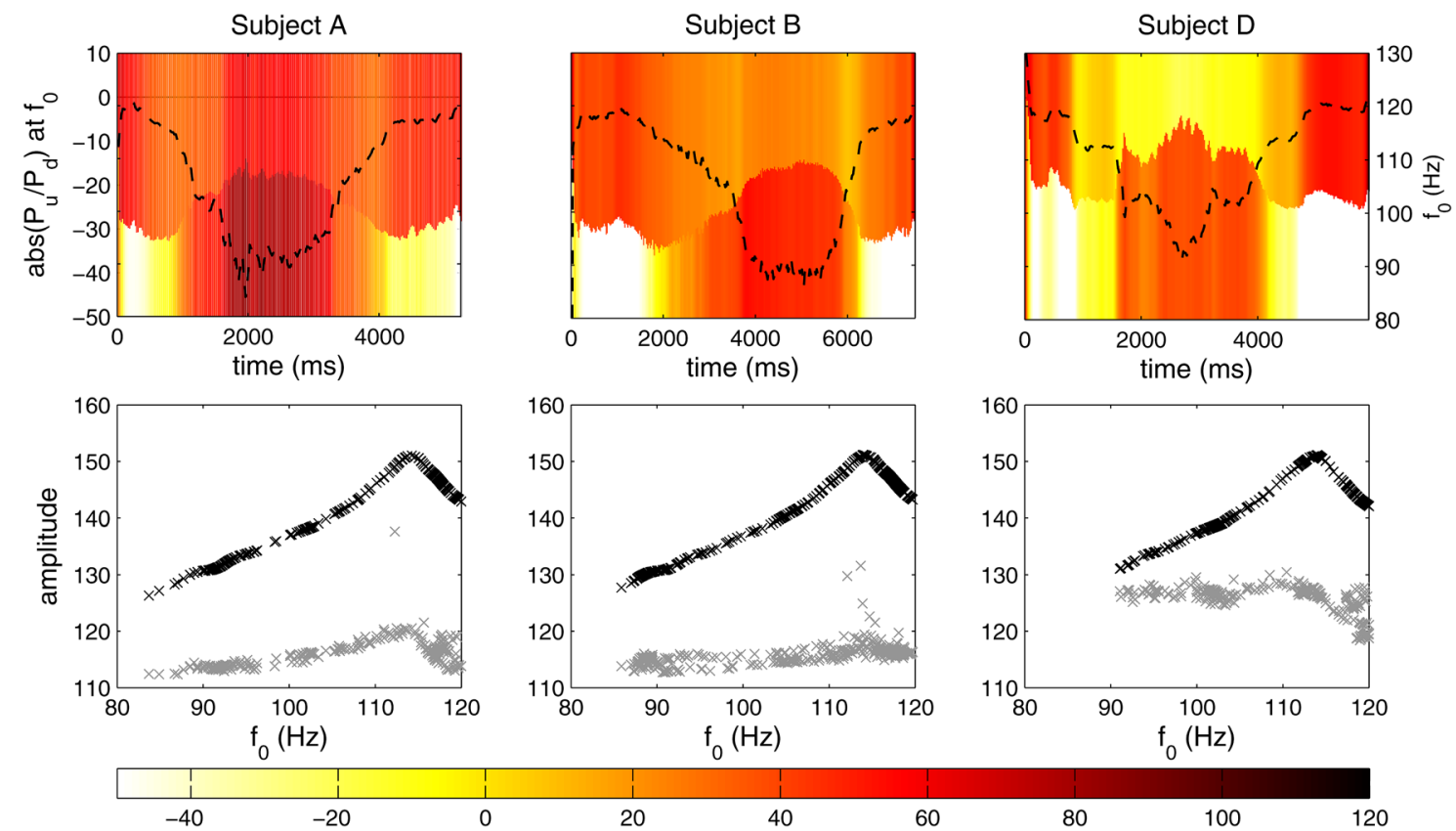

FIG. 9. (Color online) Top: SPL ratio in $\mathrm{dB}$ of the upstream to downstream pressure (boundary between color areas), $\angle G_{d}$ (top color area), $\angle G_{u-\pi}$ (bottom color area), $f_{0}$ (dashed black line) during bending from B $22(120 \mathrm{~Hz})$ for Subjects A, B, and D. Bottom: magnitude of $Z_{d}$ (black cross) and $Z_{u}$ (gray cross) at $f_{0}$ during bending. Color scale unit: degrees.

Subjects $\mathrm{A}\left(\Delta \angle G_{d}=32^{\circ}\right)$ and $\mathrm{B}\left(\Delta \angle G_{d}=31^{\circ}\right)$, while it shows more fluctuations alongside $f_{0}$ variations in Subject $\mathrm{D}\left(\Delta \angle G_{d}=76^{\circ}\right)$.

These results suggest that a small contribution of the vocal-tract at $f_{0}$ accompanies the lowest frequency part of the pitch bends in all subjects, although this effect does not reflect any significant change in $\left|Z_{u}\right|$ at the playing frequency. Regarding the phase of $G_{d}$, the small variations observed in Subjects A and B are inconsistent with the important $f_{0}$ deviation that should result in a large variation of $\angle Z_{d}$ from observation of the trombone impedance curve in Fig. 2. Accordingly, we may hypothesize that the assumed linear relationship between the lip opening area and acoustic flow is no longer valid during this bending task. This could be further interpreted as suggesting that players A and B try to maintain a constant lip vibratory mechanism during bending by preserving the phase relationship between $S_{\text {lip }}$ and $P_{d}$, thus forcing the lips into a particular regime of oscillation. Under this assumption, $\angle G_{u-\pi}$ can no longer be interpreted as an estimate of $-\angle Z_{u}$.

\section{Tone transitions}

Since the method proposed allows for a high temporal resolution tracking of $\angle G_{d}$ and $\angle G_{u-\pi}$, it particularly enables investigation of vocal-tract adjustments at tone transitions. Figure 10 shows extracted parameters near the end of a Bb4 $(475 \mathrm{~Hz})$ and the beginning of a C5 $(535 \mathrm{~Hz})$, therefore highlighting the slur transition between the two tones during the ascending arpeggio series played by Subject B. We notice that at the tone transition, and for a significant amount of time (about $100 \mathrm{~ms}$ ), the SPL ratio in decibels becomes greater than zero. This is also visible in the $p_{d}$ and $p_{u}$ waveforms where a clear boost in $p_{u}$ amplitude occurs during the transition.
Although the airflow at tone transitions may be turbulent and the continuity of the volume flow not valid at the frequency shift, this $\left|P_{u} / P_{d}\right|$ bump occurs within a significant amount of time $(300 \mathrm{~ms})$, well above the time required to reach a steady state of oscillation. We also notice an increase
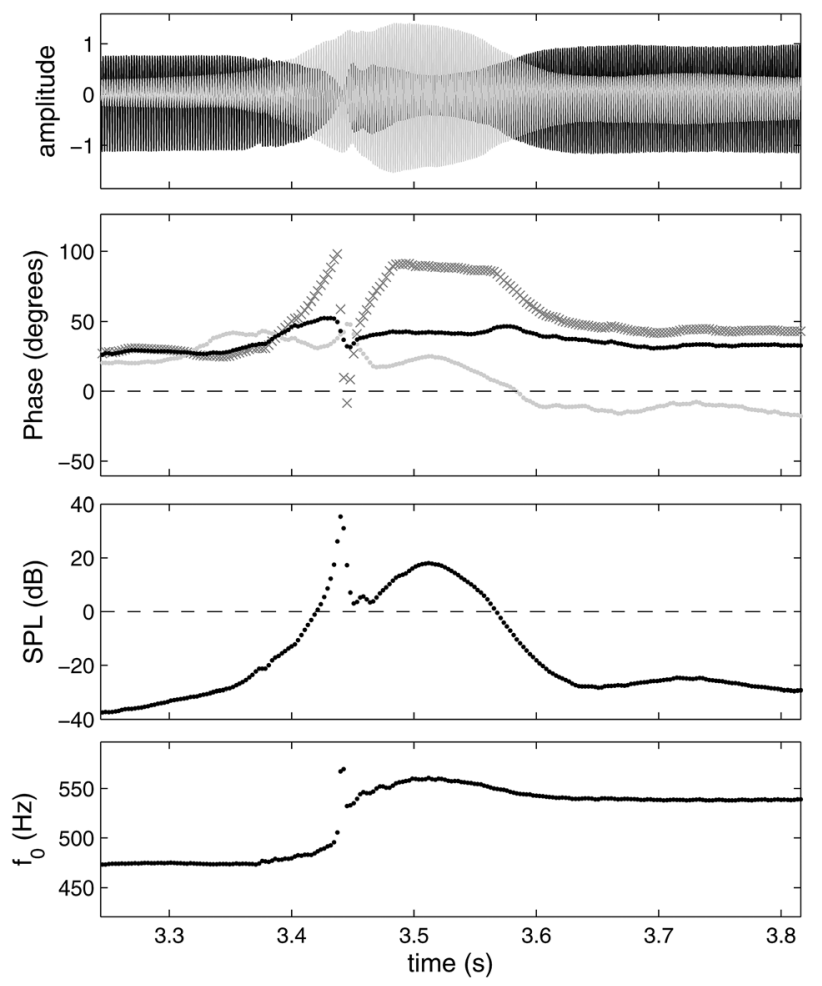

FIG. 10. Transition between B $b 4(475 \mathrm{~Hz})$ and $\mathrm{C} 5(535 \mathrm{~Hz})$ in Subject B playing an ascending slurred tone sequence. From top to bottom: waveforms of $p_{d}$ (black), $p_{u}$ (gray). $\angle G_{d}$ (dark gray), $\angle G_{u-\pi}$ (light gray), and $\angle G$ (black) at $f_{0}$; SPL ratio in $\mathrm{dB}$ of the upstream to downstream pressure; fundamental frequency. 
in the SPL ratio before the frequency changes, which suggest an increase in vocal-tract support prior to tone transition. Moreover, $\angle G_{u-\pi}$ shows smooth and continuous variations during this transitory part, whereas $\angle G_{d}$ shows a discontinuous behavior. Regarding $\angle G_{d}$, this behavior is logically explained by the sign change in $\angle Z_{d}$ between two adjacent resonances. On the other hand, the continuous character of $\angle G_{u-\pi}$ may be attributed to a synchronous adjustment of the vocal-tract resonance around $f_{0}$ resulting in a smooth phase transition of $G_{u-\pi}$. As performers were asked to slur tone transitions (no tonguing articulation), this vocal-tract adjustment might be the result of slight variations in tongue position resulting in changes in vocal-tract resonances.

\section{CONCLUSIONS}

The experimental method proposed in this article allows for evaluation of the relative amplitude and phase of the downstream and upstream pressures, and thanks to theoretical developments, enables to estimate the relative amplitude and phase of the upstream and downstream input impedances at the playing frequency, as well as the absolute phase of the downstream and upstream input impedances at $f_{0}$. This approach involves measurements of lip electrical impedance which is assumed to be in phase with lip opening area.

During arpeggio sequences, a significant increase in vocal-tract support is observed in the higher register. A careful observation of the amplitude ratio and absolute phase of the downstream and upstream input impedances for the two highest tones suggests two categories of vocal-tract tuning: (1) $Z_{u}$ amplitude large in comparison with $Z_{d}$ amplitude and $\angle Z_{u}$ close to zero at $f_{0}$, suggesting a vocal-tract resonance located near the playing frequency and overriding the effect of the trombone impedance; (2) $Z_{u}$ amplitude of the same order as $Z_{d}$ and lower values $\angle Z_{u}$ phase, suggesting a vocaltract resonance centered at a lower frequency and allowing lip oscillations at a lower value of $\angle Z$. This last tuning strategy is possibly favorable to an outward striking regime by allowing oscillations to occur closer to a mechanical resonance of the lips. This may also contribute to explain why the two players showing these characteristics were able to create higher acoustic downstream energy with lower mouth static pressure. However, this early classification may not apply to some subjects as illustrated by the results obtained for Subject E. Further investigations should be conducted in order to clarify the origin of these different strategies.

During sustained tones with variations of dynamic, a general trend involving a decrease in vocal-tract support with increase in dynamic is observed. Larger variations in $\left|P_{u} / P_{d}\right|$ ratio are observed in subjects showing highest variations in $\angle G_{u-\pi}$, which implies variations in the characteristics of the vocal-tract resonance at $f_{0}$ with increase in dynamic. Alternatively, the decrease in vocal-tract support with increase in acoustic energy produced may be explained by non-linear interactions between harmonics which participate to support lip oscillation and reduce the need for vocal-tract support at $f_{0}$.

Pitch bending tasks do not appear to involve any significant vocal-tract support at $f_{0}$. The stable phase of $G_{d}$ observed in two subjects suggests a possible interruption of the assumed linear relationship between lip opening area and the input acoustic flow. A relatively greater vocal-tract support during bending may maintain this linear relationship as shown by significant variations of $\angle G_{d}$ in one subject.

During slurred tone transitions, variations of the amplitude ratio $\left|P_{u} / P_{d}\right|$ suggest a transitory vocal-tract influence, at least prior to tone transition, indicating that upstream acoustic support is possibly needed to achieve proper slurs. Smooth variations of $\angle G_{u-\pi}$ at tone transitions also support the hypothesis of a continuous adjustment of a vocal-tract resonance around $f_{0}$ during slurs. However, the nature of this transitory vocal-tract coupling should be interpreted with care as the nature of the volume flow at the frequency shift is quite uncertain.

Although these experimental results provide relevant insights regarding the potential importance of vocal-tract tuning in brass performance, they also require further investigation in order to better understand the nature of the interaction between an upstream resonance and the vibrating lips, as well as the influence of an upstream coupling on adjacent playing control parameters (static mouth pressure, lip tension, etc.) In this context, artificial player systems offer a great experimental platform to study different aspects of the sound production chain independently from each other. In particular, the influence of amplitude and phase of an upstream resonance around the playing frequency on the behavior of artificial lips has been the object of a recent study on an artificial trombone player system. ${ }^{41}$

\section{ACKNOWLEDGMENTS}

The authors would like to thank the Centre of Interdisciplinary Research in Music Media and Technology, the Schulich School of Music and the Natural Sciences and Engineering Research Council of Canada for helping fund this project. Finally, we would like to thank Philippe Depalle for his help with some theoretical aspects of this paper.

\section{APPENDIX}

$$
\frac{\left|\angle G_{d}-\angle G\right|}{\left|\angle G_{u-\pi}-\angle G\right|}=\frac{\left|\angle\left(P_{d}-P_{u}\right)-\angle P_{d}\right|}{\left|\angle\left(P_{d}-P_{u}\right)-\angle P_{u}-\pi\right|}
$$

Define $\epsilon$ such that $\angle P_{d}\left(f_{0}\right)=0$ and $\angle P_{u}\left(f_{0}\right)=\epsilon-\pi$, calling $p_{d}(t)$ and $p_{u}(t)$ the fundamental harmonics of the downstream and upstream pressures of amplitude $a_{d}$ and $a_{u}$, respectively,

$$
\begin{aligned}
\Delta p(t) & =p_{d}(t)-p_{u}(t) \\
& =a_{d} \cos \left(\omega_{0} t\right)-a_{u} \cos \left(\omega_{0} t-\pi+\epsilon\right) .
\end{aligned}
$$

For $\epsilon$ small, applying the cosine Taylor series we obtain

$$
\begin{aligned}
\cos \left(\omega_{0} t-\pi+\epsilon\right) & =-\cos \left(\omega_{0} t+\epsilon\right) \\
& \simeq-\cos \left(\omega_{0} t\right)+\epsilon \sin \left(\omega_{0} t\right) .
\end{aligned}
$$

Consequently,

$$
\Delta p(t)=\left(a_{d}+a_{u}\right) \cos \left(\omega_{0} t\right)-a_{u} \epsilon \sin \left(\omega_{0} t\right),
$$


which leads to

$$
P_{d}\left(f_{0}\right)-P_{u}\left(f_{0}\right)=\Delta P\left(f_{0}\right)=\frac{a_{d}+a_{u}}{2}+j \frac{a_{u} \epsilon}{2} .
$$

Therefore, for $\epsilon$ small, applying the arctangent Taylor expansion,

$$
\angle \Delta P\left(f_{0}\right)=-\operatorname{atan}\left(\frac{a_{u} \epsilon}{a_{d}+a_{u}}\right) \simeq \frac{a_{u} \epsilon}{a_{d}+a_{u}} \simeq \frac{\epsilon}{1+\frac{a_{d}}{a_{u}}} .
$$

Substituting Eq. (A2) into Eq. (A1) leads to

$$
\begin{aligned}
\frac{\left|\angle\left(G_{d}\left(f_{0}\right)\right)-\angle G\left(f_{0}\right)\right|}{\left|\angle\left(G_{u-\pi}\left(f_{0}\right)\right)-\angle G\left(f_{0}\right)\right|} & =\left|\frac{\frac{\epsilon}{1+\left(a_{d} / a_{u}\right)}}{\frac{\epsilon}{1+\left(a_{d} / a_{u}\right)}+\pi-\epsilon-\pi}\right| \\
& =\left|-\frac{a_{u}}{a_{d}}\right|=\left|\frac{Z_{u}\left(f_{0}\right)}{Z_{d}\left(f_{0}\right)}\right|
\end{aligned}
$$

when $\epsilon$ is close enough from zero, which implies that $\angle P_{d}\left(f_{0}\right)-\angle P_{u}\left(f_{0}\right)$ is close to $\pi$. For the measured data presented in this paper, $\angle P d\left(f_{0}\right)-\angle P u\left(f_{0}\right)$ ranges between 80 and $180^{\circ}$, which corresponds to an estimation accuracy of between $70 \%$ and $100 \%$ (as determined by direct comparison of the estimated and exact expressions). Thus, this approximation is satisfactory to give a visual estimation of the amplitude ratio by looking at the relative distance between $\angle G_{d}, \angle G_{u-\pi}$, and $\angle G$. For Figs. 3 and 4 , this approximation can also be directly compared to measurements of the $\left|P_{u} / P_{d}\right|$ ratio.

${ }^{1}$ S. J. Elliot and J. M. Bowsher, "Regeneration in brass instruments," J. Sound Vib. 83, 181-217 (1982).

${ }^{2}$ A. H. Benade, "Chapter 35: Air column, reed, and player's windway interaction in musical instruments," in Vocal Fold Physiology, Biomechanics, Acoustics, and Phonatory Control, edited by I. R. Titze and R. C. Scherer, (Denver Center for the Performing Arts, Denver, CO), pp. 425-452.

${ }^{3}$ J. Backus, "The effect of player's vocal tract on woodwind instrument tone," J. Acoust. Soc. Am. 78, 17-20 (1985).

${ }^{4}$ T. D. Wilson, "The measured upstream impedance for clarinet performance and its role in sound production," Ph.D. thesis, University of Washingtonx, Seattle, WA (1996).

${ }^{5} \mathrm{C}$. Fritz and J. Wolfe, "How do clarinet players adjust the resonances of their vocal tracts for different playing effects?," J. Acoust. Soc. Am. 118, 3306-3315 (2005).

${ }^{6}$ G. P. Scavone, A. Lefebvre, and A. R. da Silva, "Measurement of vocaltract influence during saxophone performance," J. Acoust. Soc. Am. 123, 2391-2400 (2008).

${ }^{7}$ P. Guillemain, C. Vergez, D. Ferrand, and A. Farcy, "An instrumented saxophone mouthpiece and its use to understand how an experienced musician plays," Acta Acust. Acust. 96, 622-634 (2005).

${ }^{8}$ J. M. Chen, "Vocal tract interactions in woodwind performance," Ph.D. thesis, University of New South Wales, Sydney, Australia (2009).

${ }^{9}$ F. G. Campos, Trumpet Technique (Oxford University, New York, 2005), pp. $82-88$.

${ }^{10}$ L. E. Loubriel, Brass Singers: The Teaching of Arnold Jacob (Scholar Publisher, Lisle, IL, 2011).

${ }^{11}$ A. I. King, J. Ashby, and C. Nelson, "Laryngeal function in wind instruments: The brass," J. Voice 3, 65-67 (1989).

${ }^{12}$ M. S. Mukai, "Laryngeal movements while playing wind instruments," in Proc. International Symposium on Musical Acoustics, Tokyo, Japan (1992), pp. 239-242.
${ }^{13}$ R. Rydell, M. Karloson, A. Milesson, and L. Schalén, "Laryngeal activity during wind instrument playing: video endoscopic documentation," Log. Phon. Vocol. 21, 43-48 (1996).

${ }^{14}$ P. H. Dejonckere, F. Orval, R. Miller, and R. Sneppe, "Mécanisme oscillatoire de la glotte dans le jeu de cor (Oscillatory mechanisms of the glottis in French horn performance)," Brass Bull. 41, 28-35 (1983).

${ }^{15}$ J. M. Chen, J. Smith, and J. Wolfe, "Pitch bending and glissandi on the clarinet: Roles of the vocal tract and partial tone hole closure," J. Acoust. Soc. Am. 126, 1511-1520 (2009).

${ }^{16}$ J. M. Chen, J. Smith, and J. Wolfe, "Saxophonists tune vocal tract resonances in advanced performance techniques," J. Acoust. Soc. Am. 129, 415-426 (2011).

${ }^{17}$ A. Z. Tarnopolsky, N. H. Fletcher, L. Hollenberg, L. Lange, J. Smith, and J. Wolfe, "Vocal tract resonances and the sound of the Australian didgeridoo (yidaki) I. Experiment," J. Acoust. Soc. Am. 119, 1194-1204 (2006).

${ }^{18}$ J. Wolfe, A. Z. Tarnopolsky, N. H. Fletcher, L. C. L. Hollenberg, and J. Smith, "Some effects of the player's vocal tract and tongue on wind instrument sound," in Proc. Stockholm Music Acoustics Conference 2003, Stockholm, Sweden (2003), pp. 307-310.

${ }^{19}$ T. Kaburagi, N. Yamada, T. Fukui, and E. Minamiya, "A methodological and preliminary study on the acoustic effect of a trumpet player's vocal tract," J. Acoust. Soc. Am. 130, 536-545 (2011).

${ }^{20}$ S. Adachi and M. A. Sato, "Trumpet sound simulation using a twodimensional lip vibration model," J. Acoust. Soc. Am. 99, 1200-1209 (1996).

${ }^{21}$ J. M. Chen, J. Smith, and J. Wolfe, "Do trumpet players tune resonances of the vocal tract?," J. Acoust. Soc. Am. 131, 722-727 (2012).

${ }^{22}$ H. L. F. Helmholtz, On the Sensations of Tone (Dover, New York, 1954), pp. $95-102$.

${ }^{23}$ N. H. Fletcher, "Autonomous vibration of simple pressure-controlled valve in gas flows," J. Acoust. Soc. Am. 93, 2172-2180 (1993).

${ }^{24}$ F. C. Chen and G. Weinreich, "Nature of the lip reed," J. Acoust. Soc. Am. 99, 1227-1233 (1996).

${ }^{25}$ D. C. Copley and W. J. Strong, "A stroboscopic study of lip vibrations in a trombone,” J. Acoust. Soc. Am. 99, 1219-1226 (1996).

${ }^{26}$ S. Yoshikawa, "Acoustical behavior of brass player's lips," J. Acoust. Soc. Am. 97, 1929-1939 (1995).

${ }^{27}$ J. Gilbert, S. Ponthus, and J. F. Petiot, "Artificial buzzing lips and brass instruments: Experimental results," J. Acoust. Soc. Am. 104, 1627-1632 (1998).

${ }^{28}$ V. J. Cullen, J. Gilbert and D. M. Campbell, "Brass instruments: linear stability analysis and experiments with an artificial mouth," Acta Acust. 86, 704-724 (2000).

${ }^{29} \mathrm{P}$. Fabre, "Un procédé électrique percutané dinscription de laccolement glottique au cours de la phonation: Glottographie de haute fréquence (A percutaneous process for the monitoring of glottal contact during phonation: High frequency glottography)," Bulletin de l'Académie Nationale de Médecine (Bulletin of the National Academy of Medicine) 66-69 (1957).

${ }^{30}$ A. H. Benade and P. L. Hoekje, "Vocal tract effects in wind instrument regeneration,” J. Acoust. Soc. Am. 71, S91 (1982).

${ }^{31}$ S. Yoshikawa and Y. Muto, "Lip-wave generation in horn players and the estimation of lip-tissue elasticity," Acust. Acta Acust. 89, 145-162 (2003).

${ }^{32}$ P. Sidlof, "Fluid-structure interaction in human vocal folds," Ph.D. thesis, Charles University in Prague, Prague, Czech Republic (2007).

${ }^{33}$ L. Mongeau, N. Franchek, C. H. Coker, and R. A. Kubli, "Characteristics of a pulsating jet through a small modulated orifice, with application to voice production," J. Acoust. Soc. Am. 102, 1121-1133 (1997).

${ }^{34}$ S. Bromage, M. Campbell, and J. Gilbert, "Open areas of vibrating lips in trombone playing," Acust. Acta Acust. 96, 603-613 (2010).

${ }^{35}$ T. Hézard, V. Fréour, T. Hélie, R. Caussé, and G. P. Scavone, "Synchronous visualization of multimodal measurements on lips and glottis: Comparison between brass instruments and the human voice production system," J. Acoust. Soc. Am. 133, 3417 (2013).

${ }^{36}$ J. Backus and N. Hundley, "Harmonic generation in the trumpet," J. Acoust. Soc. Am. 49, 509-519 (1971).

${ }^{37}$ J. Wolfe and J. Smith, "Acoustical coupling between lip valves and vocal folds," Acoust. Aust. 36, 23-27 (2008).

${ }^{38}$ R. A. Krakow, "Nonsegmental influences on velum movement patterns: Syllables, sentences, stress, and speaking rate," Technical Report SR-117/ 118, Haskins Laboratories Status Report on Speech Research (1994).

${ }^{39}$ C. A. Macaluso and J. P. Dalmont, "Trumpet with near-perfect harmonicity: Design and acoustic results," J. Acoust. Soc. Am. 129, 404-414 (2011).

${ }^{40}$ In orchestral writing the trombone is generally a non-transposing instrument.

${ }^{41}$ V. Fréour, N. Lopes, R. Caussé, and G. P. Scavone, "Simulating different upstream coupling conditions on an artificial trombone player system using an active sound control approach,” J. Acoust. Soc. Am. 133, 3269 (2013). 